\title{
Baeza, ejemplo de gestión en la conservación del patrimonio documental
}

En octubre de 2016, tras una visita técnica realizada por los especialistas del Instituto Andaluz del Patrimonio Histórico al Archivo Municipal del Ayuntamiento de Baeza, con el fin de asesorar en materia de conservación y confirmar la viabilidad de recuperar una selección de documentos de gran valor histórico pero que se encontraban en un estado de conservación deficiente, comienza la relación de ambas instituciones. Por el momento, tres años de buen entendimiento confirman el acierto de un proyecto de conservación cuya clave del éxito radica en que en ningún momento ha tenido fecha de caducidad.

María José Calvo Rentero | Archivo Municipal de Baeza

María Campoy Naranjo| Instituto Andaluz del Patrimonio Histórico

URL de la contribución <http://www.iaph.es/revistaph/index.php/revistaph/article/view/4370>

En la ya dilatada trayectoria del Taller de patrimonio documental y bibliográfico (PDyB) del Instituto Andaluz del Patrimonio Histórico (IAPH), son muchas las instituciones que han puesto sus bienes en manos de los técnicos especialistas, reflejando el cambio de mentalidad de estas entidades y de la sociedad en general, sobre la necesidad de preservar y conservar el patrimonio escrito.

Es innegable que estas instituciones realizan un gran esfuerzo por recuperar y transmitir sus bienes más valiosos, si bien las actuaciones - por falta de recursos principalmente, pero también por la ausencia de políticas de conservación frente a otras necesidades más acuciantes- suelen limitarse a intervenciones emblemáticas concretas. Restaurada su pieza estrella, se da por concluida la contribución al patrimonio cultural, condenando al olvido otros destacados bienes documentales que también peligran.

La experiencia del Taller de patrimonio documental y bibliográfico del IAPH indicaba que ninguna institución pública ni privada apuesta por dar continuidad al proyecto, a sabiendas de la necesidad y por la indicación expresa de los técnicos especialistas. La excepción ha venido del Ayuntamiento de Baeza y de su envite por recuperar su patrimonio documental sin fechas ni plazos.

La relación del IAPH con el Archivo Municipal del Ayuntamiento de Baeza se inició a raíz de la visita téc- nica efectuada por los técnicos del IAPH en octubre de 2016, con el fin de asesorar en materia de conservación y confirmar la viabilidad de recuperar una selección de documentos de gran valor histórico y estado de conservación deficiente.

Después de tres años de colaboración puede hablarse de un perfecto entendimiento entre ambas instituciones. Hasta la fecha se ha seguido una operativa de restauraciones individualizadas, de tal manera que, sólo cuando finaliza una intervención, el levantamiento del depósito temporal del documento permite depositar otro, concediendo un amplio margen para cada una de las actuaciones requeridas a nivel administrativo y técnico. Con esta dinámica se están gestionando los trabajos de restauración del cuarto documento histórico que propone el Archivo.

La Carta de Alfonso XI al corregidor de la ciudad sobre las dehesas de Jaén y Baeza (Gibraltar, 1349/10/13), la Carta del juicio entre Yuçaf Aben Berga y el concejo de Baeza sobre monedas y alcabalas (Baeza, 1381/2/26) y el documento por el que Alfonso XI ordena a los empadronadores de la moneda forera de Baeza que abonen el salario de los escribanos que confeccionan los padrones (Sevilla, 1340/6/24) son los tres documentos ya restaurados.

Estos proyectos de conservación no tienen como único objetivo la recuperación material y funcional. De acuerdo 
con la metodología del IAPH, se profundiza en su conocimiento mediante el estudio histórico y de sus valores culturales, y a través de cuantos estudios técnicos y científicos son requeridos, teniendo en cuenta que el marco histórico de los mencionados documentos está en relación con los profundos cambios políticos y sociales que se produjeron en la Baja Edad Media, y una etapa tan destacada merece un estudio en profundidad.

Iniciativas como la del Ayuntamiento de Baeza son un ejemplo para otras instituciones. La apuesta por la recuperación del patrimonio cultural debe ser una tarea planificada y prolongada en el tiempo, una actividad sistemática dentro de la gestión de cualquier entidad responsable de la conservación de bienes de interés cultural.

El Archivo de Baeza era consciente, desde hacía tiempo, de la situación en la que se encontraban muchos de sus documentos: plagas, hongos, humedades, deterioros estructurales debidos al tiempo y a la mala utilización, volúmenes mal encuadernados, pérdidas, etc. Eran algunos de los síntomas que el Ayuntamiento, desde su desconocimiento, presuponía que existían.

Conscientes de la importancia que la conservación y restauración de documentos se decide, por iniciativa de la archivera responsable del Archivo de Baeza, emprender acciones para la recuperación patrimonial: en primer lugar implantando un programa de formación continua y adecuada para el personal que trabajaba en el Archivo, y así poder solucionar aspectos fundamentales de su trabajo como son el ingreso de documentación, cuyo estado había que identificar, y el mantenimiento del material ya existente en sus dependencias.

Después de unos años de formación, en 2017 se presentó, desde el propio Archivo, una propuesta al Ayuntamiento de Baeza en la que se especificaba la importancia de una revisión completa y una evaluación de los fondos por parte del IAPH. Tras la aprobación de esta propuesta y dada la concienciación existente, el propio Ayuntamiento, a través de la concejalía de hacienda a cargo de Rodrigo Checa Lorite, se aprobó una partida presupuestaria extra para la restauración de los documentos que pudieran ejecutarse en un año.
Esta medida histórica, porque nunca se había llevado a cabo en la larga trayectoria del Archivo, sentó precedentes. Gracias a esta ayuda las restauraciones son continuas y constantes, sin objeción alguna. Por primera vez, desde la alcaldía de Baeza, el equipo de M. ${ }^{a}$ Dolores Marín Torres ha tomado cartas directas en un asunto que nunca había sido considerado en unos presupuestos municipales $y$, con ello, se ha dado el paso definitivo al cambio y a la concienciación que tantos archivos necesitan.

Hoy en día, la importancia de este proyecto radica en que en ningún momento ha tenido fecha de caducidad, que sigue vigente y está sirviendo para concienciar al resto de instituciones públicas y privadas de la localidad acerca de la importancia de la conservación y restauración de sus bienes, al municipio en general y, principalmente, a perpetuar el patrimonio documental de Baeza. 